Original Research Paper

\title{
Forces at Internal Combustion Engines
}

\author{
${ }^{1}$ Relly Victoria V. Petrescu, ${ }^{2}$ Raffaella Aversa, ${ }^{3}$ Bilal Akash, ${ }^{4}$ Ronald B. Bucinell, \\ ${ }^{5}$ Juan M. Corchado, ${ }^{6}$ John Kaiser Calautit, \\ ${ }^{2}$ Antonio Apicella and ${ }^{1}$ Florian Ion T. Petrescu \\ ${ }^{1}$ ARoTMM-IFToMM, Bucharest Polytechnic University, Bucharest, (CE), Romania \\ ${ }^{2}$ Advanced Material Lab, Department of Architecture and Industrial Design, \\ $x, 81031$ Aversa (CE), Italy \\ ${ }^{3}$ Dean of School of Graduate Studies and Research, American University of Ras Al Khaimah, UAE \\ ${ }^{4}$ Union College, USA \\ ${ }^{5}$ University of Salamanca, Spain \\ ${ }^{6}$ Department of Mechanical Engineering, University of Sheffield, Sheffield, UK
}

Article history
Received: 01-01-2017
Revised: 06-01-2017
Accepted: 27-04-2017
Corresponding Author:
Florian Ion T. Petrescu
ARoTMM-IFToMM,
Bucharest Polytechnic
University, Bucharest, (CE),
Romania
Email: scipub02@gmail.com

\begin{abstract}
The paper presents an algorithm to set the parameters of the dynamics of the classic mechanism the main of internal combustion. It shows the distribution of the forces (on the main mechanism of the engine) on engines with internal combustion. Dynamic, the gears can be distributed in the same way as forces. Practically, in the dynamic regimes, the velocities have the same synchronization as forces. The method shall be applied separately for two distinct situations: When the engine is working on a compressor and in the system of the motor. For the two individual cases, two independent formulae are obtained for the dynamic cinematic forces (gearbox). The calculations shall be made for an engine with a single cylinder. The change of speed in the dynamics feels like a variation of the angular speed of the engine. It is more difficult to be taken into account (theoretically) effect on engine with several cylinders.
\end{abstract}

Keywords: Kinematics, Forces, Velocities, Powers, Engines, Efficiency, Geometry, Synthesis, Yield

\section{Introduction}

The first functional motor vehicle was invented in 1769 by Nicolas Joseph Cugnot under the name of Cugnot's fardier but it was not until the second half of the nineteenth century and the progress of the industrial revolution that personal motor vehicles developed and eventually Their current automobile name. The birth of the automobile was made by the adaptation of a steam engine on an autonomous chassis but technical and social problems delayed its development. Boiler space, inadequate materials at high pressures and frames with poor vibration were the main technical obstacles and the perceived and real danger of these devices on the roads at the time led to binding legislation such as the Locomotive Act in the United Kingdom.

The automotive adventure began in the Aosta Valley (Italy), where the first successful experiments took place in 1864. It was Innocent Manzetti of Aosta who made a steam car that could travel along the streets. The newspapers of Aosta and Turin spoke of it between 1869 and 1870 .

Very quickly this type of prototypes was successful thanks to other directors and led to that in 1895 about 350 automobiles circulated on the French territory, against 75 in Germany and only 80 in the United States. It was a time when we were not really talking about automobile manufacturers, but rather bodybuilders because the chassis was purchased separately.

The first automobiles produced and marketed are steam (The Obedient of Amédée Bollée in 1873) and the first prototypes using the new engines less explosive in the middle of the $1880 \mathrm{~s}$ under the impulse of a French engineer Édouard Delamare-Debouteville and a German engineer Gottlieb Daimler. At the same time, the development of knowledge related to electricity leads to the realization of the first electric cars: There are therefore three propulsion modes competing at the turn of the twentieth century. The steam is rapidly displaced 
and the rapid development of the performance of electric cars is halted by the absence of any notable progress in the storage of energy, it is therefore the combustion engine that prevails over the other modes of propulsion. This era is that of the race to speed and it is first the electric car that is illustrated there (The Jamais Contente is the first to cross the bar of $100 \mathrm{~km} \mathrm{~h}^{-1}$, in 1899) before being Supplanted by the car with explosion engine. It is also the birthplace of the first automobile competitions, such as Paris-Rouen in 1894. The automobile remains a luxurious product, to the binding use, used on infrastructures totally inadequate.

The history of the car has created and lived different trades. At this point in history, building a car was a collective affair in which bodybuilders, but also wheelwrights, locksmiths, trunk makers, saddlerssaddlers, saddlers, tackers and painters were involved together. Everything was tailor-made, bodywork fitting to the chassis, passing through the seats or luggage stowed in the back for the first trips. Two factors will contribute to its development: The gradual covering of roads in town and then in the countryside in order to facilitate the use of bicycles and cars and the development of new production methods (Taylorism, Fordism), which lead to the first car of large series, the Ford T. This definitely poses the imprint of the automobile on society of the twentieth century. Innovations follow one another, but there is no fundamental conceptual change. The main lines of the current series car are traced by Lancia in 1922 with the Lambda with self-supporting body and independent front suspension, Chrysler in 1934 with the Airflow which introduces aerodynamics in the series car, Citroën and the development of The Traction Avant from 1934, then the introduction of the disc brakes on the DS in 1955, or by Porsche and the gearbox with conical synchronizers of the 356 .

In every country, the automobile experienced a long period of enthusiasm; Average driving time has seen strong growth with a US driving boom; From 1970 to 2004, the distance traveled by an average American has almost doubled $(+85 \%)$, from 8,700 to 16,100 $\mathrm{km} /$ year. Then this trend stabilized until 2011 and a slight decrease in $2012(1,000 \mathrm{~km} /$ year less per driver). On this basis, a prospective scenario called "Ongoing Decline" postulated in 2013 that by imitation of the current young generation, the decline in appetite for the automobile could continue. In several countries, the desire to own a car or driver's license seems to be diminishing, especially in urban areas. This movement is most pronounced in Generation Y: 16-34 year olds take less of the wheel; $-23 \%$ from 2001 to 2009 of the number of $\mathrm{km} /$ year traveled.

In the West, the fastest pace of market growth was linked to the craze for the "Roaring Twenties" car. It was then marked by crises (crash of 1929, World War II, energy crises) which redistributed industrial maps several times, favoring regroupings and caused the return to grace of small cars; The peak of this phenomenon being reached in Germany in the 1950s with micro-cars such as the Isetta.

The Thirty Glorieuses revived the rise of all the automobile sectors, reflecting an increase in the choice, production and accession to the automobile, by the opening of the use of credit in the years 1960, momentum stopped by the first oil shock. This, coupled with rising road insecurity, will have lasting consequences on the relationship between the automobile and society, leading in particular to a strong wave of speed regulation.

Then the socio-environmental aspects (ecology, road safety) became issues, both for the design of cars and transport at the end of the twentieth century and for consumer choices, leading to innovations such as downsizing and hybrid engines Launched on the Toyota Prius (1997) and then the Honda Insight (1999).

The car and the individual motorized mobility could still technically evolve and possibly in the future disappear in favor of other means of transport in a city or a "world without cars", with effects that some prospectivists try to imagine. For example, four $\mathrm{PhD}$ students from the Laboratoire d'Urbanisme, Lausanne Federal Polytechnic School (Bahrami Farzaneh and Skjonsberg Matthew) are working on the actors or premises of a possible change and the potential future of the urban spaces that would be freed. In densely inhabited areas, certain behaviors seem to indicate a disaffection for the car, with a decrease in sales and a decline in the rate of young people passing or wishing to pass their driving license (Amoresano et al., 2013; Anderson et al., 1984; Bishop, 1950; Choi and Kim, 1994; De Falco et al., 2013a; 2013b; Ganapathi and Robinson, 2013; Heywood, 1988; Hrones, 1948; Karikalan et al., 2013; Leidel, 1997; Mahalingam and Ramesh Bapu, 2013; Naima and Liazid, 2013; Narasiman et al., 2013; Petrescu and Petrescu, 2005; 2011; 2013a; 2013b; 2013c; 2013d; 2014; Petrescu et al., 2005; Petrescu, 2012a; 2012b; Rahmani et al., 2013; Ravi and Subramanian, 2013; Ronney et al., 1994; Sapate and Tikekar, 2013; Sethusundaram et al., 2013; Zahari et al., 2013).

The automotive industry plays an important role in the industry of several major industrialized countries. It sometimes takes on a strategic aspect given its historical proximity to military industries, the importance it can take in the gross domestic product and the employment of certain countries (the United States, France, Britain, Germany) and the image that the automobile can give from a country to the outside world (Italian design, American way of life, German mechanics, Japanese zero defect, French innovation, Etc.). 
The automotive sector is now organized into large groups of final assemblers that use parts from a large number of suppliers and subcontractors but generally maintain the heaviest industrial activities internally Such as sheet metal work or engine production.

In 2013, total production is 83 million passenger cars, $20 \%$ more than in 2008 .

OEMs, with a turnover of more than $€ 10$ billion, are Denso, Delphi, Visteon, Valeo, Faurecia, Magna International and Bosch.

The sale of automobiles is also an important economic sector. The diffusion of automobile production is generally ensured by a network of independent companies, for the national manufacturers, or via an importer, with the same type of network, for the others. The importer may not be a subsidiary of the manufacturer. The network is generally assured of regional exclusivity. This classic pattern of distribution has been undermined by free competition rules in many countries and has led to the development of automotive agents.

In addition, automobile consumption accounts for the largest share of consumer credit, accounting for $37 \%$ of the volume of credit used in the purchase of new cars in France in 2001 and $66 \%$ second-hand cars.

From the moment of its birth, the automobile was perceived as a dangerous invention. Its evolution, designed to respond to the problems raised by road safety and prevention as it was perceived over the years, was tortuous. Apart from managing the road network or the behavior of users, the problems raised are those of passive safety - the protection of occupants in the event of a road accident - and active safety-prevention in order to avoid the accident. Historically, only this last aspect has been continuously improved; the improvement in passive safety did not begin until the $1970 \mathrm{~s}$, the period of fatal accidents.

The first cars went at the speed of the horse but unlike him, were unable to be stopped quickly, especially on an unsuitable road network. The difficulty of their conduct and the fear of this new craft have led some countries to legislate very strictly in this matter, by imposing on the cars of beings preceded by a man on foot ("Locomotive Act" in the United Kingdom for example).

The change in perception by the general public occurred when the automobile became more democratic. From the $1920 \mathrm{~s}$ to the $1960 \mathrm{~s}$, road safety, or its absence, did not move anyone. Speed is free outside agglomeration and banal uncivil behaviors. In France, the hecatomb had a peak in 1972 , with 16,548 deaths that year, marked by the creation of the inter ministerial road safety organization. A significant drop was subsequently achieved through vehicle upgrades, speed limits, seat belt use, through the extension of motorways and the reduction of the consumption of psychotropic drugs and notably alcohol, reaching about 6,000 in the early $2000 \mathrm{~s}$.

This development observed in developed countries is far from widespread; the extremely rapid increase in the number of vehicles in circulation in developing countries (China, India, etc.) or the lack of intervention in road safety in others (Russia, Iran, etc.), a road death rate that is still rising worldwide and could become one of the three leading causes of death. The World Health Organization (WHO) published the first global road safety report of 178 countries in June 2009, concluding that road accidents cause 1.2 million deaths each year and 20-50 million traumas not fatal. More than $90 \%$ of accidents occur in low- and middle-income countries, which account for less than half of the world's car fleet.

Changes in suspensions, tires and the introduction of electronic stability control systems and other driving aids have resulted in interesting improvements in vehicle handling and road safety. Automobiles whose handling is considered dangerous by automotive journalists have become extremely rare, whereas their frequency in the $1960 \mathrm{~s}$ was more significant, inter alia, due to the virtual disappearance of the rear engine architecture.

It appears that future safety improvements will focus less on limiting the damage caused by accidents than on reducing their number and impact. Indeed, advances in electronics and the efforts of manufacturers and OEMs have given rise to very sophisticated equipment that is or should gradually become widespread on all vehicles. The best known of these is the ABS, which avoids the blocking of the wheels during a significant braking of the vehicle and which keeps control of its trajectory. More recently, automotive manufacturers are attempting to address the overriding problem of driver behavior by integrating active systems to mitigate driver failures either by direct solicitation (systems that detect the driver's level of alertness), Or by replacing it (e.g., via anti-collision systems that can brake without driver intervention or completely autonomous cars).

The systems offered by Mobileye (composed of a smart camera and an LED display on the dashboard) offer several types of visual and audible alerts for driving assistance:

- Front Collision Warning (ACF)

- Collision Warning Pedestrian and cyclist (ACP)

- Security Distance Alert (ADS)

- Line Crossing Alert (AFL), also known as Unintentional Line Crossing Alert (AFIL)

- Intelligent Headlight Control Function (CPI)

- Speed Limit Indication Function (ILV)

The previously described active or passive safety systems contribute to the production of safer cars. The effectiveness of these systems is tested and measured 
during crash tests by international bodies such as EuroNCAP for the European Community. A safe car for its passengers is now a selling point for car manufacturers who are making great efforts on the issue.

True progress has been made in recent years, particularly with regard to "airbags" or pretensioner belts avoiding a violent shock of the driver on the steering wheel. On the cabriolets, bows behind the seats go up very quickly when the calculator considers there is a risk of turning. Car manufacturers also work on even more efficient systems. A major advance in this area is that the number of airbags has increased from two to eight in a few years. Now no more cars come out without being equipped.

If the passengers are better and better protected, it was not necessarily the case of pedestrians. The new safety standards take into account the damage caused to them in a frontal impact. These changes have led manufacturers to develop front hoods and shields capable of absorbing some of the energy from the impact in order to limit the damage inflicted on pedestrians. Some vehicles are equipped with pyrotechnic triggers that raise the cowl a few centimeters in an accident, preventing or limiting the impact of a pedestrian with the engine block.

The relationship between the automobile and road safety is not only to assess the safety of the vehicle alone, but also to study the interaction between vehicles and accidents. From this point of view, $4 \times 4 \mathrm{~s}$, SUVs, vans and minivans are frequently criticized because of the obstruction of the visual field of the other drivers they cause. But it is especially their dangerousness in the event of a collision with a light car or a vulnerable user is accused to them.

In a collision between two vehicles, they must dissipate all their kinetic energy, in the form of mechanical energy (deformation of vehicles) or kinetic (possible rebound of one of the vehicles). Kinetic energy being proportional to mass, these heavy vehicles cause much greater damage than a lighter vehicle at equal speed. The dangerous nature of this type of vehicle for vulnerable road users, especially pedestrians, is linked to two aspects: On the one hand, their lower road behavior (lower avoidance capacity, longer braking distances) increases the risk of collision with A pedestrian in urban areas where the speed is less than $60 \mathrm{~km} \mathrm{~h}^{-1}$ and on the other hand the design of these vehicles is more dangerous for pedestrians in accidents in areas where the speed is less than $60 \mathrm{~km} \mathrm{~h}^{-1}$.

This proven problem of design is highlighted by EuroNCAP shock tests with a pedestrian and sometimes accentuated by an accessory to questionable utility, the bull bar.

The owners of these cars are therefore regarded by some as endangering the life of others and choosing their own safety at the expense of the safety of other road users, an idea contradicted by certain statistics of accidents. Conversely, advocates of this type of vehicle argue that average behavior does not condemn all drivers. One can't judge a guilty individual by default, especially rolling in a homologated vehicle. If there is an inadequacy, then it should be sought in the objectives set by the administrations whose role is to ensure the safety of the population.

The globalization of the automobile on a global scale since the end of the last century poses problems concerning the global warming, pollution, safety and health of people and especially the weakest (pedestrians, cyclists, children, The elderly, etc.), the use of natural resources and in particular the depletion of oil reserves.

The impact on the environment is increasing as the weight of the car increases. Indeed a heavy vehicle has a greater energy requirement than a small one. The aerodynamics of the vehicle become preponderant when the speed increases, the vehicles with high frontal surface are then disadvantaged.

The search for improvements to the engines is guided by two contradictory objectives: The public authorities impose increasingly stringent environmental standards, which run counter to the decline in consumption.

For example, obstacles to exhaust (catalytic converter, particulate filter) lead to an increase in consumption. Since the public awareness of the environmental impact of automobiles, the level of compromise has gradually shifted from a strong desire to reduce local pollutants, which are a direct source of diseases and deaths, from the 1970 to $1990 \mathrm{~s}$ which is now focused on reducing $\mathrm{CO}_{2}$ emissions.

The aspect of local pollutants is dealt with on a European scale by the successive emission standards (Euro standards 1 to 6), while the aspect of $\mathrm{CO}_{2}$ emissions is currently processed through the intermediary the overall objectives of manufacturers, or via national tax legislation.

By its manufacture, maintenance and recycling, the automobile generates gray energy pollution and contributes to the scarcity of non-renewable resources, such as oil, terbium, hafnium, silver, antimony, Palladium, gold, zinc, indium, tin, lead, lithium, tantalum, copper, uranium, nickel and fossil fuels.

Around the automobile, account must be taken of all the infrastructure and logistics necessary for the manufacture, transport, maintenance, repair, recycling, advertising or organization of car shows or in another register, To treat the injured during accidents or for the police control of the motorists during their movements. This includes, in particular, the manufacture and maintenance of factories, garages, gas stations, washing stations, car repair shops, machinery, tools, spare parts, Maintenance or cleaning to manufacture, maintain and 
recycle the automobile and all stages of transport, from the point of extraction of the raw materials to the raw material processing plants, from the processing plants of the raw materials to the manufacturing sites, At the place of manufacture at the place of sale of the automobile, machinery, tools, spare parts, maintenance products or cleaning.

Other indirect products are also to be taken into account, which put an end to a lot of pollution, as each establishment (factory, garage, petrol station, bank, police station, etc. Cars or their occupants who may be injured in an accident or who commit offenses, use office equipment, computers, toners, telephones, cleaning and maintenance products, medicines and Products for caring for the wounded, electricity (air conditioning, heating, etc.) which themselves have to be manufactured or produced and often transported.

The most widely known environmental impact is air pollution from exhaust gases, which causes respiratory diseases and contributes to global warming. With domestic heating appliances, the automobile has become the main contributor to urban pollution and smog, a chronic situation in most major cities, especially in an anticyclonic period.

According to the French Agency for Environmental Health Safety (AFSSET), atmospheric pollution, linked to almost a third of pollutant emissions from cars, would be responsible each year for the death of 6,500 to 9,500 people in France. Another European study, CAFE CBA: Baseline analysis 2000 to 2020, states that only diesel fine particles are responsible in France for the deaths of 42,090 people every year. The main releases of automotive exhaust systems are: Carbon dioxide $\mathrm{CO}_{2}$ contributes to the greenhouse effect, global warming and climate change, but is not a pollutant in the sense of a toxic or irritating gas.

Carbon monoxide (CO): It causes migraines, dizziness, impaired vision and decreases blood oxygenation. At high concentration, it is deadly, hence the danger of idling a motor in an enclosed garage. It is rapidly diluted and degraded to $\mathrm{CO}_{2}$ in the atmosphere.

Oxides of nitrogen (NOx): In humans, this irritating gas decreases immune defense and alters lung function. It is the precursor to the formation of ozone in the lower layers of the atmosphere, by its decomposition in the presence of solar radiation. Ozone is an irritant gas and toxic at high concentrations.

Unburned hydrocarbons (HC): In humans, they cause respiratory tract infections and allergies. They are the other precursors to the formation of ozone.

Suspended particles, linked to combustion in diesel engines. Soot particles, for example, increase the risk of respiratory disease and cancer according to epidemiological studies. In 2013, the International
Agency for Research on Cancer (IARC) classifies fine diesel particulate matter as a human carcinogen.

Sulfur dioxide $\mathrm{SO}_{2}$ : In countries where the sulfur content of fuels is limited or not limited, this is one of the main causes of acid rain.

Lead. In countries and regions where the addition of lead to gasoline is not prohibited, a large proportion (between 65 and $99 \%$ of children living in areas at risk and about $50 \%$ even among those least exposed) to chronic lead. The introduction of unleaded gasoline in developed countries rapidly translated into a reduction in blood lead levels of about $50 \%$ among urban adults who were less susceptible to lead than children.

Benzene: Road transport in general is by far the largest emitters of benzene and in Europe there has been a direct link between the decrease in the maximum benzene content in fuels (halved in 2000) and a decrease in the concentration of benzene Background of benzene in the atmosphere.

These releases are subject to regulations in different countries, for example the Euro emission standard for Europe. These standards are attached to standardized driving cycles, such as the NEDC or its American counterparts, which are supposed to represent typical road behavior. The thresholds adopted by these regulations are steadily declining over the years.

For a given model, a gasoline car consumes a greater volume of fuel than a diesel because gasoline has a lower energy density than diesel. But also, the thermodynamic efficiency of a petrol engine is lower. Almost all drivers observe consumption higher than those measured according to standards in fixed driving cycles, which are however those used commercially.

For these reasons, it is imperative that one can calculate exactly the engine output to may increase permanently (Petrescu and Petrescu, 2005; 2011; 2013a; 2013b; 2013c; 2013d; 2014; Petrescu et al., 2005; Petrescu, 2012a; 2012b).

\section{Presents the Algorithm for the Otto Engine in Compressor System}

It presents an algorithm to set the parameters of the dynamics of the classic mechanism the main of internal combustion. It shows the distribution of the forces (on the main mechanism of the engine) on engines with internal combustion. Dynamic, the gears can be distributed in the same way as forces. Practically, in the dynamic regimes, the gears have the same synchronization as forces. The method shall be applied separately for two distinct situations: When the engine is working on a compressor and in the system of the engine. For the two individual cases, two independent formulae are obtained for the dynamic cinematic forces (gearbox). The calculations shall be made for an engine 
with a single cylinder. It is more difficult to be taken into account (theoretically) effect on engine with several cylinders. Start with the mechanism of the primary engine in the compressor (when the motor mechanism operates the crank, Fig. 1).

Now we are going to watch forces distribution in this case (Fig. 1). The motor force $F_{m}$, perpendicular in B on the crank 1, is divided in two components: $F_{n}$ and $F_{\tau}$. The normal force, $F_{n}$, is transmitted along the rod (connecting rod) from point $\mathrm{B}$ to the point $\mathrm{C}$. The tangential force, $F_{\tau}$, is a rotating force which made the rotation of the connecting rod (element 2). The $F_{n}$ (normal) force from the point $C$ is divided as well in two components: $F_{u}$ and $F_{R}$. The utile force, $F_{u}$, moves the piston and the radial force, $F_{R}$, press on the cylinder barrel in which guides the piston. Dynamic, the velocities can be distributed in the same way as forces. Practically, in the dynamic regimes, the velocities have the same timing as the forces: $v_{m}$ : is the motor velocity; $v_{n}$ : is the normal velocity, which is transmitted along the connecting rod; $v_{\tau}$ : is the tangential velocity, which produces the rotation of the element; $v_{R}$ : is the radial velocity, who press on the cylinder barrel in which guides the piston (This velocity produces a radial vibration); $v_{u}$ : The utile velocity, moves the piston (when the mechanism is in compressor system). We can write the following relations of calculation (1-2) (Petrescu and Petrescu, 2005; 2011; 2013a; 2013b; 2013c; 2013d; 2014; Petrescu et al., 2005; Petrescu, 2012a; 2012b):

$$
\left\{\begin{array}{l}
\left\{\begin{array}{l}
v_{m} \equiv v_{B}=l_{1} \cdot \omega \\
v_{n}=v_{m} \cdot \sin \left(\phi-\phi_{2}\right)=v_{m} \cdot \sin (\psi-\phi) \\
v_{\tau}=v_{m} \cdot \cos \left(\phi-\phi_{2}\right)=-v_{m} \cdot \cos (\psi-\phi) \\
v_{u}=v_{n} \cdot \sin \psi=v_{m} \cdot \sin (\psi-\phi) \cdot \sin \psi \\
v_{R}=v_{n} \cdot \cos \psi=v_{m} \cdot \sin (\psi-\phi) \cdot \cos \psi
\end{array}\right. \\
\left\{\begin{array}{l}
v_{C}^{\text {Din.c }}=v_{u}=l_{1} \cdot \omega \cdot \sin (\psi-\phi) \cdot \sin \psi \\
v_{C}^{\text {Din.c }}=v_{C} \cdot D^{c}=\frac{l_{1} \cdot \omega \cdot \sin (\psi-\phi)}{\sin \psi} \cdot D^{c}
\end{array} \Rightarrow D^{c}=\sin ^{2} \psi\right. \\
\Rightarrow w^{c} \equiv \omega^{\text {Din.c }}=\omega \cdot D^{c} ; \dot{D}^{c} \\
=2 \cdot \sin \psi \cdot \cos \psi \cdot \dot{\psi}=\sin 2 \psi \cdot \dot{\psi} \\
\left\{\begin{array}{l}
\frac{d}{d t}\left[v_{C} \cdot \sin \psi=l_{1} \cdot \omega \cdot \sin (\psi-\phi)\right] \\
\Rightarrow a_{C} \cdot \sin \psi+v_{C} \cdot \cos \psi \cdot \dot{\psi}=l_{1} \cdot \omega \cdot \cos (\psi-\phi) \cdot(\dot{\psi}-\omega) \\
\Rightarrow a_{C}=\frac{l_{1} \cdot \omega \cdot \cos (\psi-\phi) \cdot(\dot{\psi}-\omega)}{\sin \psi} \\
l_{l} \cdot \omega \cdot \sin (\psi-\phi) \cdot \cos \psi \cdot \dot{\psi} \\
-\frac{\sin { }^{2} \psi}{d t}
\end{array}\right. \\
a_{C}^{\text {Din.c }}=\frac{d}{d t}\left(v_{C}^{\text {Din.c }}\right)=\frac{d}{d t}\left(v_{C} \cdot D^{c}\right)=a_{C} \cdot D^{c}+v_{C} \cdot \dot{D}^{c}
\end{array}\right.
$$

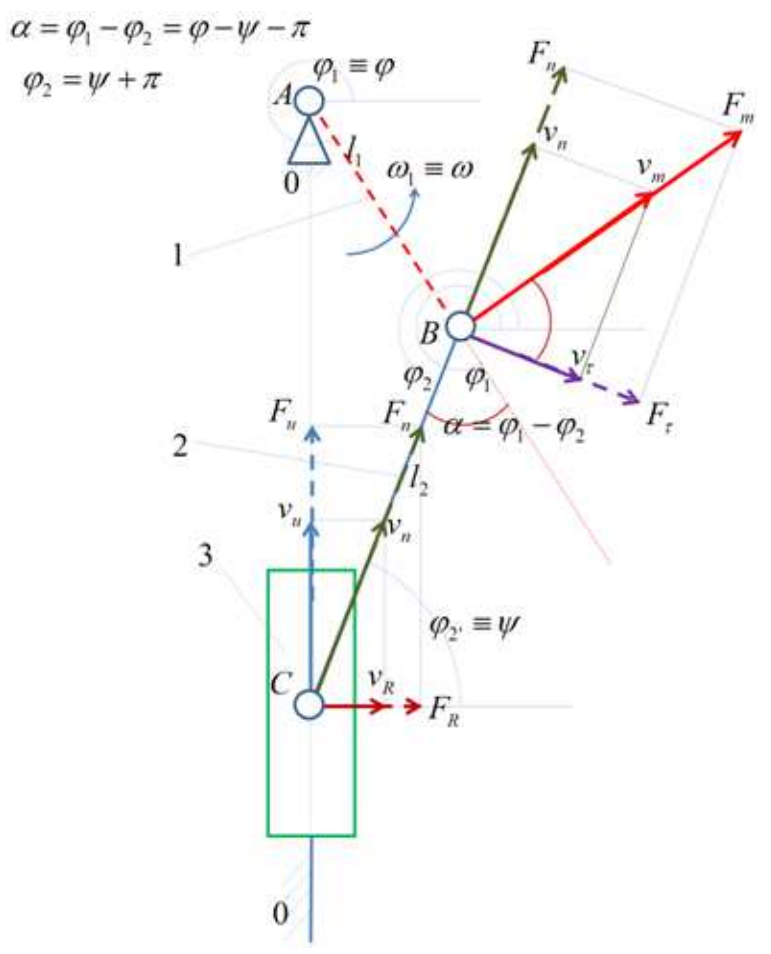

Fig. 1. The forces and velocities distribution in engine mechanism, when it is operated of the crank (element 1)

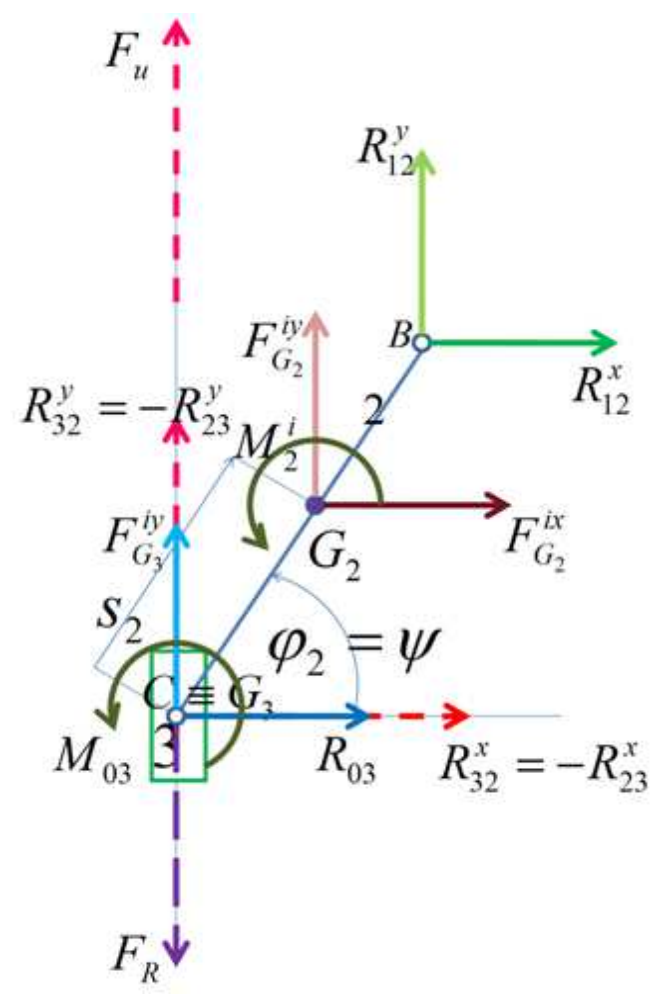

Fig. 2. The forces of mechanism, when it is operated from the crank (element 1) 


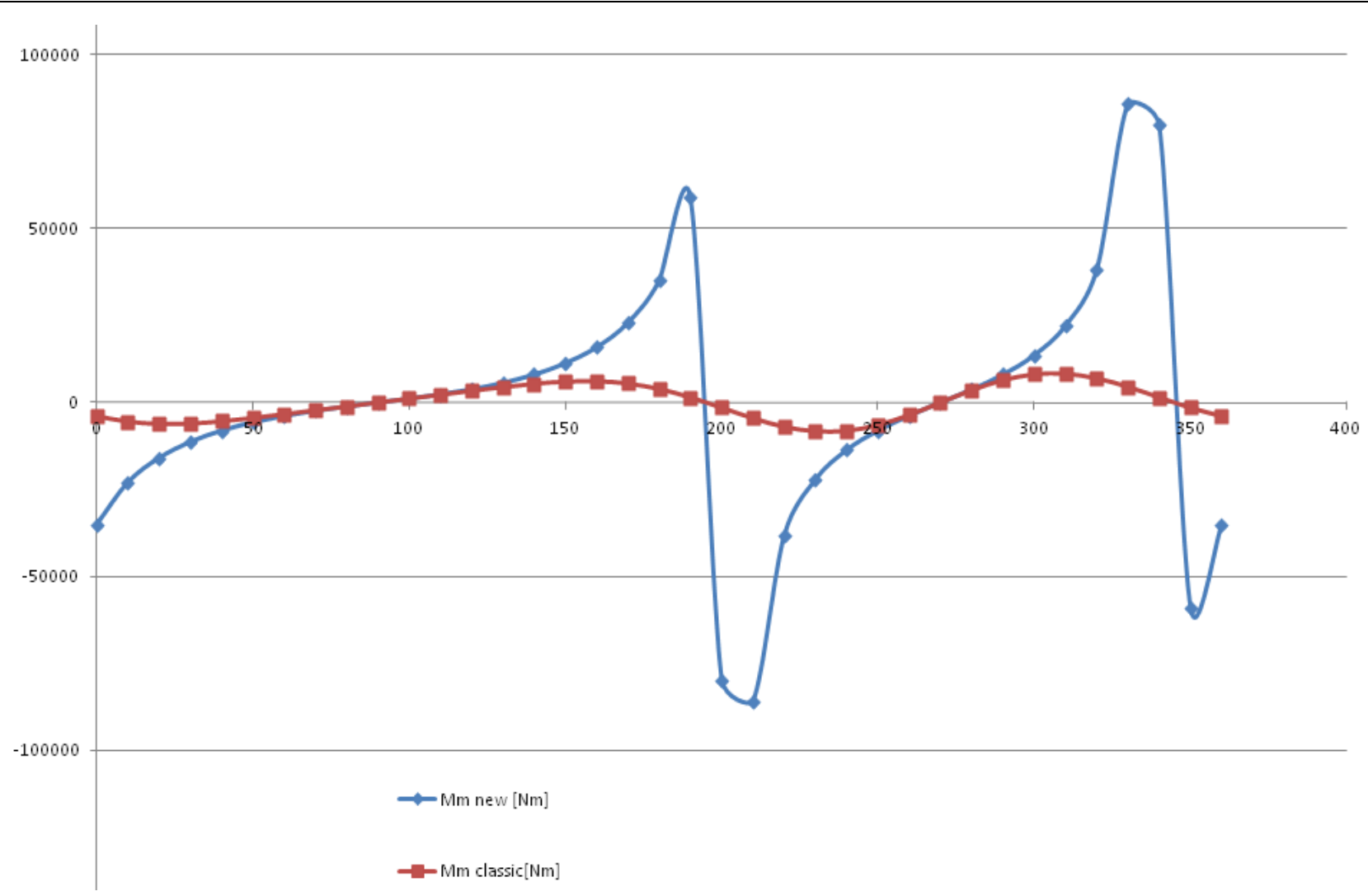

Fig. 3. The classical torque and the new torque

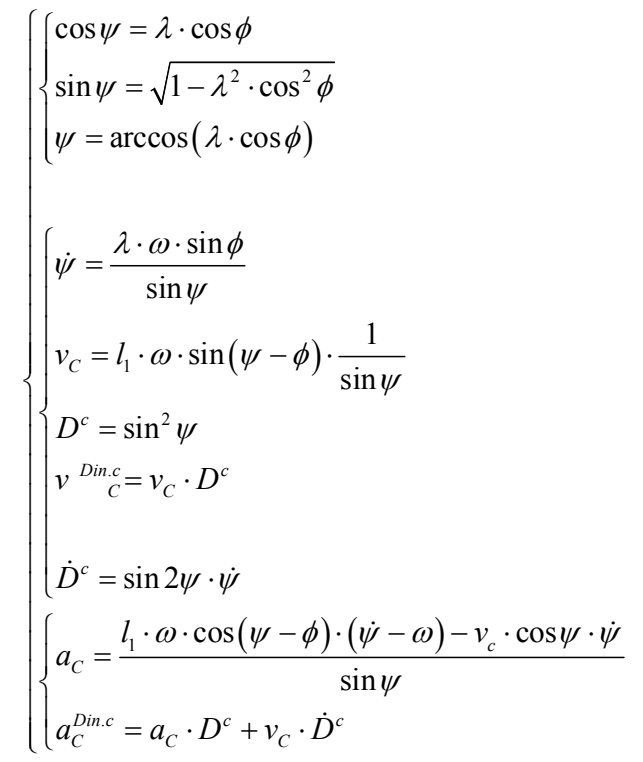

The forces of mechanism can be seen in the Fig. 2 .

Express motive power through conservation of powers of all the mechanism (system 3) (Petrescu and Petrescu, 2005; 2011; 2013a; 2013b; 2013c; 2013d; 2014; Petrescu et al., 2005; Petrescu, 2012a; 2012b):

$$
\begin{aligned}
& \sum P=0 \Rightarrow F_{m} \cdot l_{1} \cdot \omega_{1}+M_{2}^{i} \cdot \omega_{2}+F_{G_{2}}^{i x} \cdot \dot{x}_{G_{2}}+ \\
& +F_{G_{2}}^{i y} \cdot \dot{y}_{G_{2}}+F_{G_{3}}^{i y} \cdot \dot{y}_{G_{3}}+F_{R} \cdot \dot{y}_{C}=0 ; \quad F_{u}=-F_{R} \Rightarrow \\
& \left\{\begin{array}{l}
F_{u}=\frac{F_{m} \cdot l_{1} \cdot \omega_{1}+M_{2}^{i} \cdot \omega_{2}+F_{G_{2}}^{i x} \cdot \dot{x}_{G_{2}}+F_{G_{2}}^{i y} \cdot \dot{y}_{G_{2}}+F_{C}^{i y} \cdot \dot{y}_{C}}{\dot{y}_{C}} \\
F=F \cdot \sin \psi \cdot \sin (\psi-\phi)
\end{array}\right. \\
& F_{u}=F_{m} \cdot \sin \psi \cdot \sin (\psi-\phi) \\
& \begin{array}{l}
\Rightarrow F_{m}=\frac{F_{C}^{i y} \cdot \dot{y}_{C}+M_{2}^{i} \cdot \omega_{2}+F_{G_{2}}^{i x} \cdot \dot{x}_{G_{2}}+F_{G_{2}}^{i y} \cdot \dot{y}_{G_{2}}}{\dot{y}_{C} \cdot \sin \psi \cdot \sin (\psi-\phi)-l_{1} \cdot \omega_{1}} \\
M_{m}=F_{m} \cdot l_{1}
\end{array}
\end{aligned}
$$

In the diagram below (Fig. 3) we compare this new torque with the classic (Petrescu and Petrescu, 2005; 2011; 2013a; 2013b; 2013c; 2013d; 2014; Petrescu et al., 2005; Petrescu, 2012a; 2012b). The new torque was determined considering the variation of velocities with forces and forces variation due to velocities (system 3).

\section{Presents the Algorithm for the Otto Engine in Motor System}

Now we will look at the main mechanism of the engine in the system with the engine (when the motor 
mechanism acting on the piston, Fig. 4). In this case, useful is one real, be produced by the piston engine (item 3). It should be noted that the drive power from now on the piston is divided in two components, normal and tangential, only a normal part being transmitted through the cone rod to the coupler $B$, where shall be divided into two other components, $F_{u}$ and $F_{c}$, out of which only useful components is turning the handle while the code by the mills of compression on crank (B) and then on the crank and bearing (A) (Petrescu and Petrescu, 2005; 2011; 2013a; 2013b; 2013c; 2013d; 2014; Petrescu et al., 2005; Petrescu, 2012a; 2012b). Dynamic, the gears can be distributed in the same way as forces. Practically, in the dynamic regimes, the gears have the same synchronization that forces: The $v_{m}$ : is the speed of the engine; $v_{n}$ : this is the normal speed, which is transmitted along the connecting rod; $v_{\tau}$ : is the speed of the tangential, which produces rod from rotating (item 2); $v_{c}$ : is the speed of compression and presses the button crank (B) and then on the crank and bearing (A); this speed produces vibrations of bearings; $v_{u}$ : the utile velocity, rotates crank (when the mechanism is in the system with the engine).

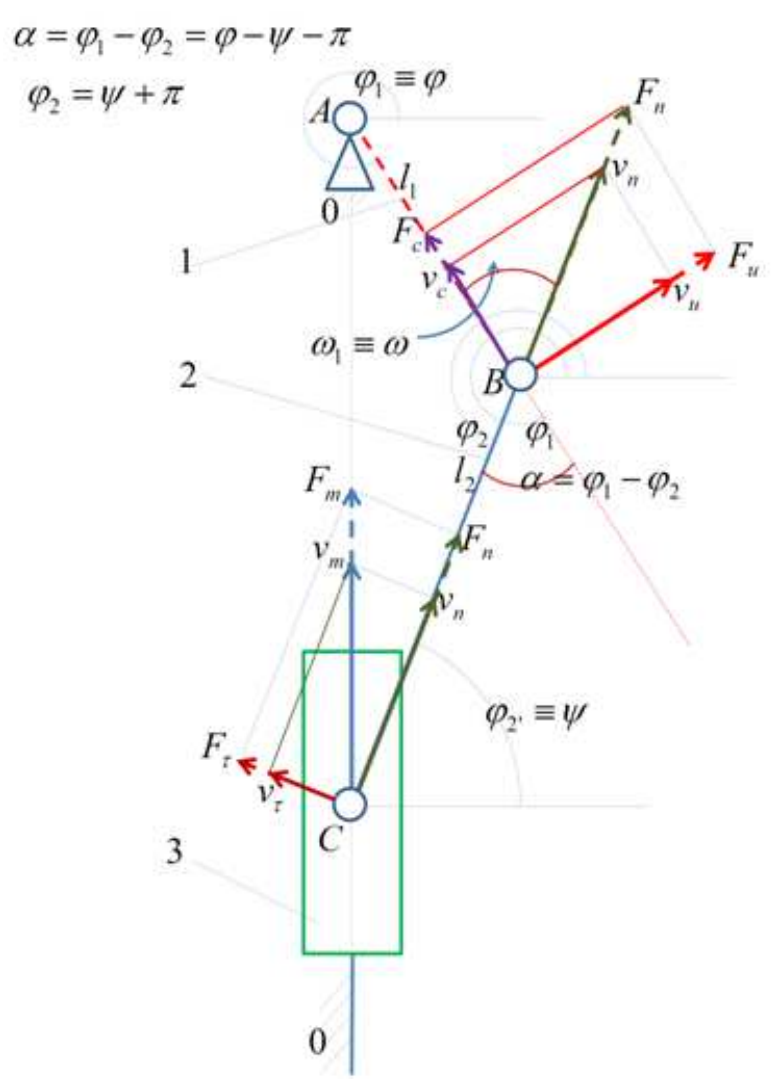

Fig. 4. The forces and velocities distribution in engine mechanism, when it is operated of the piston (element 3 )
We can write the following relations of calculation (4-5):

$$
\begin{aligned}
& \left\{\begin{array}{l}
\left\{\begin{array}{l}
v_{n}=v_{m} \cdot \sin \psi \\
v_{u}=v_{n} \cdot \sin (\psi-\phi)=v_{m} \cdot \sin \psi \cdot \sin (\psi-\phi) \\
v_{u}=\frac{l_{1} \cdot \omega \cdot \sin (\psi-\phi)}{\sin \psi} \cdot \sin \psi \cdot \sin (\psi-\phi)
\end{array}\right. \\
\left\{\begin{array}{l}
v_{u}=l_{1} \cdot \omega \cdot \sin ^{2}(\psi-\phi) \equiv v_{B}^{\text {Din.m }} \\
v_{B}^{\text {Din.m }}=v_{B} \cdot D^{m}=l_{1} \cdot \omega \cdot D^{m}
\end{array} \Rightarrow D^{m}=\sin ^{2}(\psi-\phi)\right. \\
\dot{D}^{m}=\sin 2(\psi-\phi) \cdot(\dot{\psi}-\omega) \\
\left\{\begin{array}{l}
\sin \psi \\
a_{C}=\frac{l_{1} \cdot \omega \cdot \cos (\psi-\phi) \cdot(\dot{\psi}-\omega)-v_{c} \cdot \cos \psi \cdot \dot{\psi}}{a_{C}^{\text {Din.m }}=a_{C} \cdot D^{m}+v_{C} \cdot \dot{D}^{m}}
\end{array}\right.
\end{array}\right. \\
& \left\{\begin{array}{l}
\cos \psi=\lambda \cdot \cos \phi \\
\sin \psi=\sqrt{1-\lambda^{2} \cdot \cos ^{2} \phi} \\
\psi=\arccos (\lambda \cdot \cos \phi)
\end{array}\right. \\
& \dot{\psi}=\frac{\lambda \cdot \omega \cdot \sin \phi}{\sin \psi} \\
& v_{C}=l_{1} \cdot \omega \cdot \sin (\psi-\phi) \cdot \frac{1}{\sin \psi} \\
& D^{m}=\sin ^{2}(\psi-\phi) \\
& v_{C}^{\text {Din.m }}=v_{C} \cdot D^{m} \\
& \dot{D}^{m}=\sin 2(\psi-\phi) \cdot(\dot{\psi}-\omega) \\
& \left\{\begin{array}{l}
a_{C}=\frac{l_{1} \cdot \omega \cdot \cos (\psi-\phi) \cdot(\dot{\psi}-\omega)-v_{c} \cdot \cos \psi \cdot \dot{\psi}}{\sin \psi} \\
a_{C}^{\text {Din.m }}=a_{C} \cdot D^{m}+v_{C} \cdot \dot{D}^{m}
\end{array}\right.
\end{aligned}
$$

\section{Result and Discussion (Diagrams)}

The diagrams of velocities and accelerations can be seen in the figures below. In Fig. 5 it presents the velocities (cinematic and dynamic) in compressor system and in the Fig. 7 the same velocities in motor system. The acceleration (cinematic and dynamic) can be seen in the Fig. 6 (compressor system) and Fig. 8 (motor system $) ;(\lambda=0.33 ; \mathrm{n}=3000[\mathrm{rpm}])$.

It presents an algorithm to set the parameters of the dynamics of the classic mechanism the main of internal combustion. It shows the distribution of the forces (on the main mechanism of the engine) on engines with internal combustion (Amoresano et al., 2013). Dynamic, the gears can be distributed in the same way as forces. Practically, in the dynamic regimes, the gears have the same synchronization as forces (Hrones, 1948). 


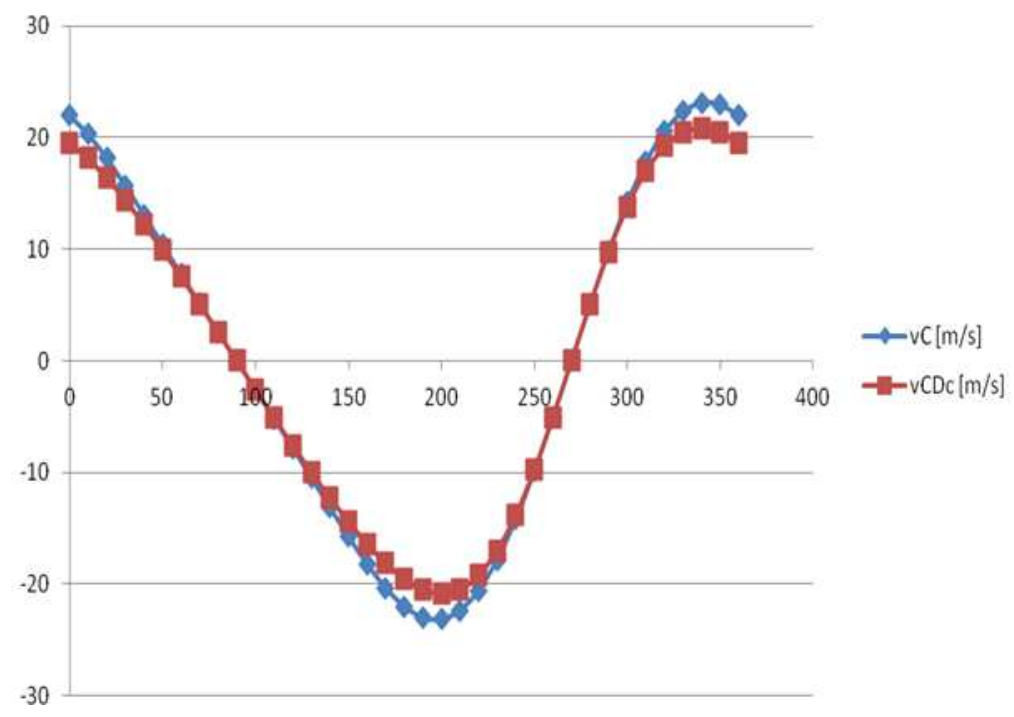

Fig. 5. The cinematic and dynamic velocities to a heat mono cylinder engine, in compressor system

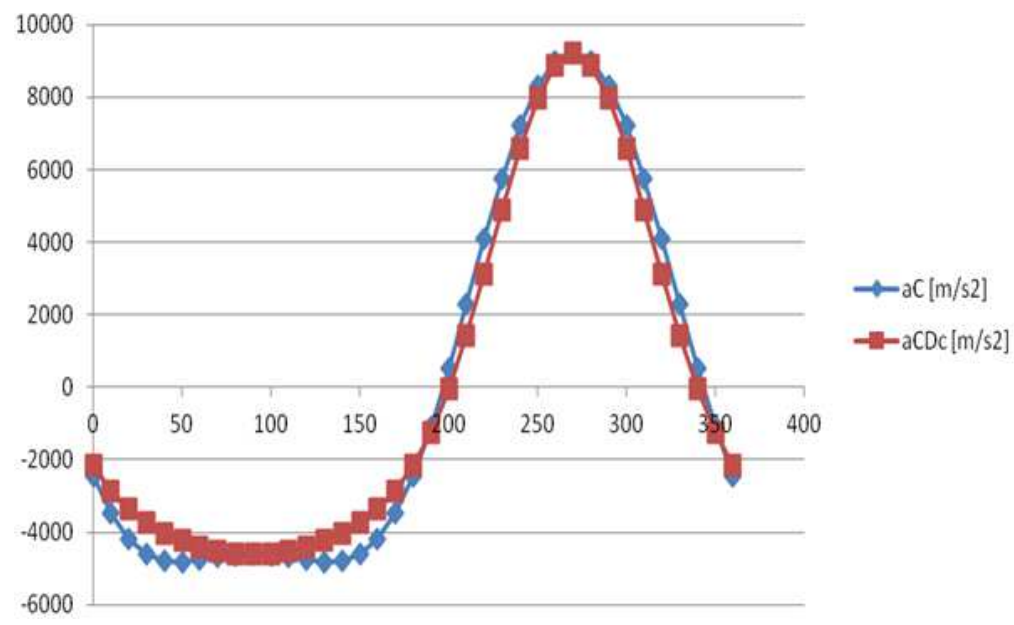

Fig. 6. The cinematic and dynamic accelerations to a heat mono cylinder engine, in compressor system

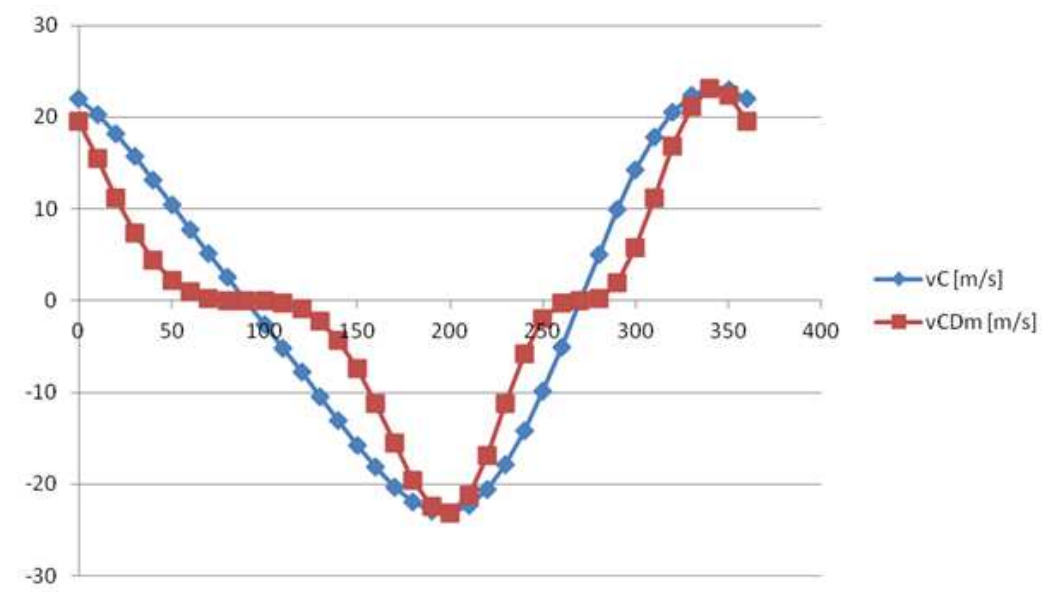

Fig. 7. The cinematic and dynamic velocities to a heat mono cylinder engine, in motor system 


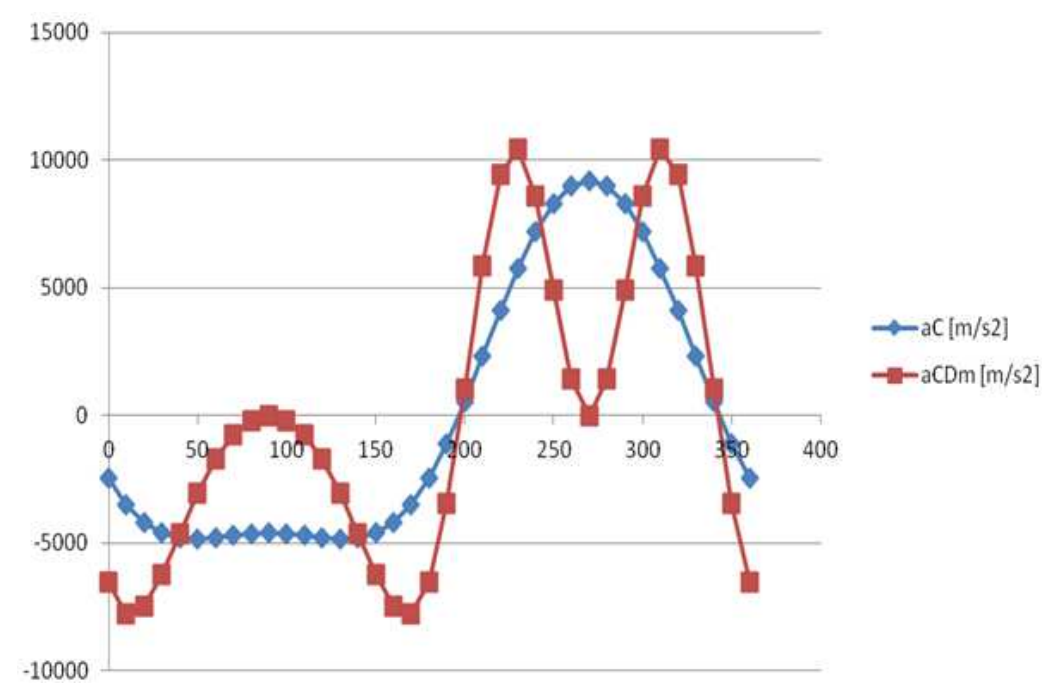

Fig. 8. The cinematic and dynamic accelerations to a heat mono cylinder engine, in motor system

The method shall be applied separately for two distinct situations: When the engine is working on a compressor and in the system of the engine. For the two individual cases, two independent formulae are obtained for the dynamic cinematic forces (gearbox). The calculations shall be made for an engine with a single cylinder. It is more difficult to be taken into account (theoretically) effect on engine with several cylinders. Start with the mechanism of the primary engine in the compressor (when the motor mechanism operates the crank, Fig. 1). Now we will look at the main mechanism of the engine in the system with the engine (when the motor mechanism acting on the piston, Fig. 4), (Petrescu and Petrescu, 2005; 2011; 2013a; 2013b; 2013c; 2013d; 2014; Petrescu et al., 2005; Petrescu, 2012a; 2012b).

In this case, useful is one real, be produced by the piston engine (item 3 ).

It should be noted that the drive power from now on the piston is divided in two components, normal and tangential, only a normal part being transmitted through the cone rod to the coupler $\mathrm{B}$, where shall be divided into two other components, $F_{u}$ and $F_{c}$, out of which only useful components is turning the handle while the code by the mills of compression on crank (B) and then on the crank and bearing (A), (Petrescu and Petrescu, 2005; 2011; 2013a; 2013b; 2013c; 2013d; 2014; Petrescu et al., 2005; Petrescu, 2012a; 2012b).

Dynamic, the gears can be distributed in the same way as forces. Practically, in the dynamic regimes, the gears have the same synchronization that forces: the $v_{m}$ : is the speed of the engine; $v_{n}$ : this is the normal speed, which is transmitted along the connecting rod; $v_{i}$ : is the speed of the tangential, which produces rod from rotating (item 2); $v_{c}$ : is the speed of compression and presses the button crank (B) and then on the crank and bearing (A); this speed produces vibrations of bearings; $v_{u}$ : the utile velocity, rotates crank (when the mechanism is in the system with the engine). Internal combustion engines of heat speeds and actual accelerations (in dynamic schemes) are different kinematic that speeds and accelerations (classical).

Dynamic, the gears can be distributed in the same way as forces. Practically, in the dynamic regimes, the gears have the same synchronization as forces.

The method shall be applied separately for two distinct situations: When the engine is working on a compressor and in the system of the engine.

Large variations appear in the engine system.

The change of speed in the dynamics feels like a variation of the angular speed of the engine.

The calculations shall be made for an engine with a single cylinder. It is more difficult to be taken into account (theoretically) effect on engine with several cylinders (Petrescu and Petrescu, 2005; 2011; 2013a; 2013b; 2013c; 2013d; 2014; Petrescu et al., 2005; Petrescu, 2012a; 2012b).

\section{Conclusion}

Internal combustion engines of heat speeds and actual accelerations (in dynamic schemes) are different kinematic that speeds and accelerations (classical).

Dynamic, the gears can be distributed in the same way as forces.

Practically, in the dynamic regimes, the gears have the same synchronization as forces.

The method shall be applied separately for two distinct situations: When the engine is working on a compressor and in the system of the engine (Zhu et al., 2007).

Large variations appear in the engine system. 
The change of speed in the dynamics feels like a variation of the angular speed of the engine.

The calculations shall be made for an engine with a single cylinder. It is more difficult to be taken into account (theoretically) effect on engine with several cylinders (Petrescu and Petrescu, 2005; 2011; 2013a; 2013b; 2013c; 2013d; 2014; Petrescu et al., 2005; Petrescu, 2012a; 2012b).

\section{Acknowledgement}

This text was acknowledged and appreciated by Dr. Veturia CHIROIU Honorific member of Technical Sciences Academy of Romania (ASTR) PhD supervisor in Mechanical Engineering and by Prof. BERTHOLD GRUNWALD, Past Director Mercedes Benz Daimler AG, Germany and Past Head Department of Automotive Engineering from Bucharest Polytechnic University, whom we thank and in this way.

\section{Funding Information}

Research contract: Contract number 36-5-4D/1986 from 24IV1985, beneficiary CNST RO (Romanian National Center for Science and Technology) Improving dynamic mechanisms internal combustion engines.

All these matters are copyrighted. Copyrights: 421qDiazjHkBu, from 01-03-2010 22:49:44; 3679vpqggvwrhm, from 04-01-2015 01:44:46; 1375 tnzjHFAqGF, from 02-09-2011 15:19:23; 398tDGpbsxgrD, from 18-02-2010 01:16:36 and 394qodGnhhtej, from 17-02-2010 13:42:18.

\section{Author's Contributions}

All the authors contributed equally to prepare, develop and carry out this manuscript.

\section{Ethics}

Authors declare that are not ethical issues that may arise after the publication of this manuscript. This article is original and contains unpublished material.

\section{References}

Amoresano, A., V. Avagliano, V. Niola and G. Quaremba, 2013. The assessment of the incylinder pressure by means of the morphodynamical vibration analysis-methodology and application. IREME J., 7: 999-1006.

Anderson, R.B., H. Kölbel and M. Rálek, 1984. The Fischer-Tropsch Synthesis. 1st Edn., Academic Press, ISBN-10: 0120584603, pp: 301.

Bishop, J.L.H., 1950. An analytical approach to automobile valve gear design. Inst. Mech. Eng. Auto-Division Proc., 4: 150-160.
Choi, J.K. and S.C. Kim, 1994. An experimental study on the frictional characteristics in the valve train system. Proceedings of the FISITA Congress, Oct. 17-21, Beijing, pp: 374-380.

De Falco, D., G. Di Massa, S. Pagano and S. Strano, 2013a. Motorcycle handlebar dynamic response: Theoretical and experimental investigation. IREME J., 7: 795-801.

De Falco, D., G. Di Massa and S. Pagano, 2013b. A full scale motorcycle dynamic rig. IREME J., 7: 519-526.

Ganapathi, P. and Y. Robinson, 2013. Experimental investigation on the performance, emission and combustion characteristics of a diesel engine fuelled with polymer oil-ethanol blends. IREME J., 7: 919-924.

Heywood, J.B., 1988. Internal Combustion Engine Fundamentals. 1st Edn., McGraw-Hill, ISBN-10: 007028637X, pp: 930.

Hrones, J.A., 1948. An analysis of dynamic forces in a cam-driver system. Trans. ASME, 70: 473-482.

Karikalan, L., M. Chandrasekaran and K. Sudhagar, 2013. Comparative studies on vegetable oil usage in C.I engines as an alternative to diesel fuel. IREME J., 7: 705-715.

Leidel, J.A., 1997. An optimized low heat rejection engine for automotive use. SAE paper No. 970068.

Mahalingam, S. and B.R. Ramesh Bapu, 2013. Experimental and emission analysis of rubber seed oil and Jatropha oil blends with diesel in compression ignition engine. IREME J., 7: 955-959.

Naima, K. and A. Liazid, 2013. Numerical investigation on combustion behaviors of direct-injection spark ignition engine fueled with CNG-hydrogen blends. IREME J., 7: 652-663.

Narasiman, V., S. Jeyakumar and M. Mani, 2013. Optimizing the compression ratio of C.I engine fuelled in sardine oil ethyl ester. IREME J., 7: 463-467.

Petrescu, F.I. and R.V. Petrescu, 2005. Determining the dynamic efficiency of cams. Proceedings of the 9th IFToMM International Symposium on Theory of Machines and Mechanisms, (TMM' 05), Bucharest, Romania, pp: 129-134.

Petrescu, F.I., R.V. Petrescu and N. Popescu, 2005. The efficiency of cams. Proceedings of the 2nd International Conference "Mechanics and Machine Elements, Nov. 4-6, Technical University of Sofia, Sofia, Bulgaria, pp: 237-243.

Petrescu, F.I. and R.V. Petrescu, 2014. Cam gears dynamics in the classic distribution. Independent $\mathrm{J}$. Manage. Product., 5: 166-185.

Petrescu, F.I. and R.V. Petrescu, 2013a. An algorithm for setting the dynamic parameters of the classic distribution mechanism. IREMOS J., 6: 1637-1641. 
Petrescu, F.I. and R.V. Petrescu, 2013b. Dynamic synthesis of the rotary cam and translated tappet with roll. IREMOS J., 6: 600-607.

Petrescu, F.I. and R.V. Petrescu, 2013c. Forces and efficiency of cams. IREME, 7: 507-511.

Petrescu, F.I. and R.V. Petrescu, 2013d. Cams with high efficiency. IREME, 7: 599-606.

Petrescu, F.I. and R.V. Petrescu, 2011. Dinamica Mecanismelor de Distributie. Create Space Publisher, USA., ISBN-10: 978-1-4680-5265-7, pp: 188.

Petrescu, F.I., 2012a. Bazele Analizei și Optimizării Sistemelor cu Memorie Rigidă-Curs și Aplicații. Create Space Publisher, USA, ISBN-10: 978-1-4700-2436-9, pp: 164.

Petrescu, F.I., 2012b. Teoria Mecanismelor-Curs si Aplicatii (editia a doua). Create Space Publisher, USA, ISBN-10: 978-1-4792-9362-9, pp: 284.

Rahmani, L., B. Draoui, M. Bouanini and E. Benachour, 2013. CFD study on heat transfer to bingham fluid during with gate impeller. IREME, 7: 1074-1079.

Ravi, S. and R. Subramanian, 2013. Diesel fuel additives: An overview. IREME, 7: 698-704.
Ronney, P.D., M. Shoda, S.T. Waida and E.J. Durbin, 1994. Throttleless premixed-charge engines: Concept and experiment. J. Automobile Eng., 208: 13-24.

Sapate, K.D. and A.N. Tikekar, 2013. Engine mapping for improvement in fuel efficiency of two stroke SI engine. IREME, 7: 392-394.

Sethusundaram, P.P., K.P. Arulshri and K. Mylsamy, 2013. Biodiesel blend, fuel properties and its emission characteristics sterculia oil in diesel engine. IREME, 7: 925-929.

Zahari, I., M.A. Abras, N.I. Mat Arishad, S.F. Zainal and M.F. Muhamad, 2013. Experimental study to identify common engine part load conditions between malaysian city driving and NEDC test. IREME, 7: 1152-1158.

Zhu, G., I. Haskara and J. Winkelman, 2007. Closedloop ignition timing control for SI engines using ionization current feedback. IEEE Trans Control Syst., 15: 416-427.

DOI: 10.1109/TCST.2007.894634 